\title{
Control of Surge in Centrifugal Compressor by Using a Nozzle Injection System: Universality in Optimal Position of Injection Nozzle
}

\author{
Toshiyuki Hirano, ${ }^{1}$ Takanori Uchida, ${ }^{2}$ and Hoshio Tsujita $^{3}$ \\ ${ }^{1}$ Production Systems Engineering Course, Tokyo Metropolitan College of Industrial Technology, 1-10-40 Higashiohi, \\ Shinagawa-ku, Tokyo 140-0011, Japan \\ ${ }^{2}$ Graduate School of Engineering, Hosei University, 3-7-2 Kajinocho, Koganei-shi, Tokyo 184-8584, Japan \\ ${ }^{3}$ Department of Mechanical Engineering, Faculty of Science and Engineering, Hosei University, Tokyo, Japan
}

Correspondence should be addressed to Toshiyuki Hirano, hirano@s.metro-cit.ac.jp

Received 20 July 2012; Revised 28 September 2012; Accepted 9 October 2012

Academic Editor: N. Sitaram

Copyright ( $\odot 2012$ Toshiyuki Hirano et al. This is an open access article distributed under the Creative Commons Attribution License, which permits unrestricted use, distribution, and reproduction in any medium, provided the original work is properly cited.

\begin{abstract}
The passive control method for surge and rotating stall in centrifugal compressors by using a nozzle injection system was proposed to extend the stable operating range to the low flow rate. A part of the flow at the scroll outlet of a compressor was recirculated to an injection nozzle installed on the inner wall of the suction pipe of the compressor through the bypass pipe and injected to the impeller inlet. Two types of compressors were tested at the rotational speeds of 50,000 rpm and 60,000 rpm with the parameter of the circumferential position of the injection nozzle. The present experimental results revealed that the optimum circumferential position, which most effectively reduced the flow rate for the surge inception, existed at the opposite side of the tongue of the scroll against the rotational axis and did not depend on the compressor system and the rotational speeds.
\end{abstract}

\section{Introduction}

In recent years, the global approach to environmental protection has progressed and the measures against the problems such as the exhaust gas of cars and the fossil fuels depletion are urgent tasks. A turbocharger, as a part of the technology dealing with environmental problems, is expected to clean the exhaust gas from automobile engines by improving combustion efficiency, and to contribute to the reduction of fuel consumption through downsizing of engine leading to the weight reduction. Therefore, the application of a turbocharger to various types of vehicle is developing rapidly. Moreover, since the centrifugal compressor, which is a main component of turbocharger, possesses higher pressure ratio in a single stage and consequently contributes to the reduction in size and weight, it is widely used for many kinds of industrial machines as well as turbochargers. Therefore, the extension of the stable operation range and the improvement of the supercharging characteristics of a centrifugal compressor are required dramatically.

The operation of a centrifugal compressor of turbocharger at a lower flow rate close to the maximum pressure ratio induces instability phenomena such as rotating stall and surge. Especially, the surge may generate enough intense vibration and noise to destroy the whole pipeline system including a compressor. Moreover, it strongly influences the performance characteristics of the compressor. As a result, the stable operation range is inevitably restricted. Therefore, several investigations [1-6] have been carried out to control the inception of instability phenomena for the purpose of the extension of stable operation range of a centrifugal compressor to the lower flow rate.

In the previous studies on the control of surge in a centrifugal compressor, the injection nozzle system was employed, in which a part of the flow in the discharge duct was recirculated to the inlet of the impeller, and controlled 


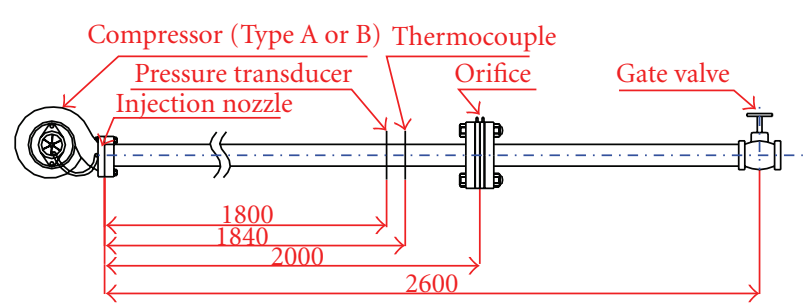

Figure 1: Experimental apparatus (unit: $\mathrm{mm}$ ).

the inceptions of rotating stall and surge [7]. Moreover, optimization of the parameters affecting on the performance of the injection nozzle system such as a position of injection has been performed [8]. Furthermore, the dependency of the optimum injection position on the rotational speed of the impeller has been investigated [9]. However, since these studies have been performed for the same turbocharger system, the universality in the characteristics of the injection nozzle has not been clarified yet.

In this study, the optimum circumferential position of injection nozzle, which most effectively reduced the flow rate for the surge inception, was investigated for two types of compressors at rotational speeds of $50,000 \mathrm{rpm}$ and $60,000 \mathrm{rpm}$ to examine the universality of the optimum circumferential position of injection nozzle. In addition, the influences of the injection on the fluctuating property of the flow field before and after the surge inception were investigated by examining the frequency of static pressure fluctuation on the wall surface.

\section{Experimental Apparatus}

The experimental apparatus used in this study is shown in Figure 1. The configurations and the specifications of centrifugal impellers for two types of centrifugal compressors Type A and Type B are shown in Figure 2 and Table 1, respectively. The outlet blade angle is measured from a radial direction. The compressed air supplied from the screw compressor was used to drive the turbine impeller which revolved the compressor impeller through the corotating axis. A part of the air at the exit of the compressor scroll, which was compressed by the centrifugal impeller and the vaneless diffuser, was recirculated into the injection nozzle installed at the impeller inlet through the bypass pipe. Then, the remaining air was discharged through the delivery duct. The inner diameter of the injection nozzle used in this study is $4 \mathrm{~mm}$. The injection nozzle is installed on the inner wall of the suction pipe of compressor, which is movable in the circumferential direction as shown in Figure 3.

\section{Experimental Method}

The origin of a circumferential position of the injection nozzle indicated by $\mathrm{TT}(0)$ is located at the corresponding position to the scroll tongue portion as shown in Figure 4. The circumferential position of the injection nozzle TT has the positive value in the rotational direction of the centrifugal
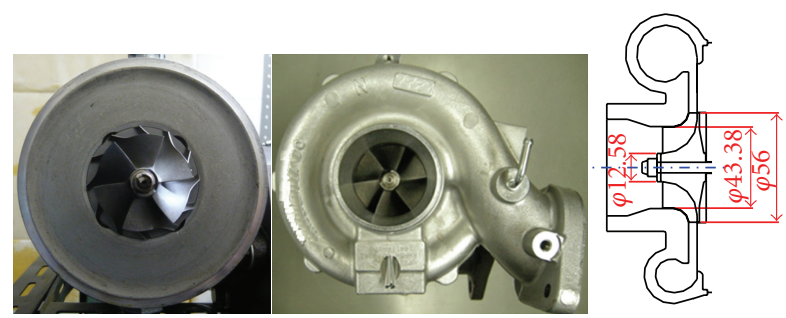

(a) Type A
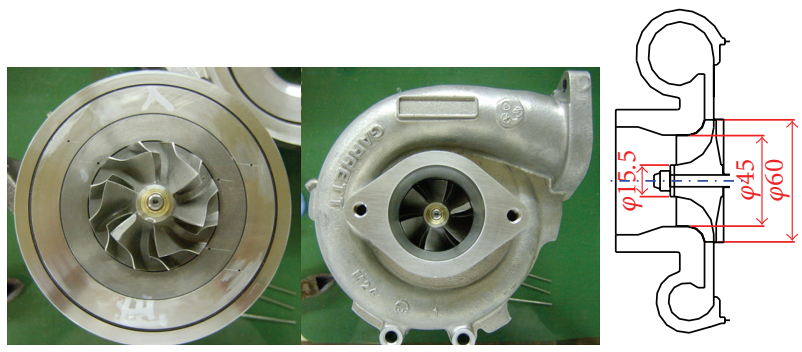

(b) Type B

Figure 2: Tested impeller (unit: $\mathrm{mm}$ ).

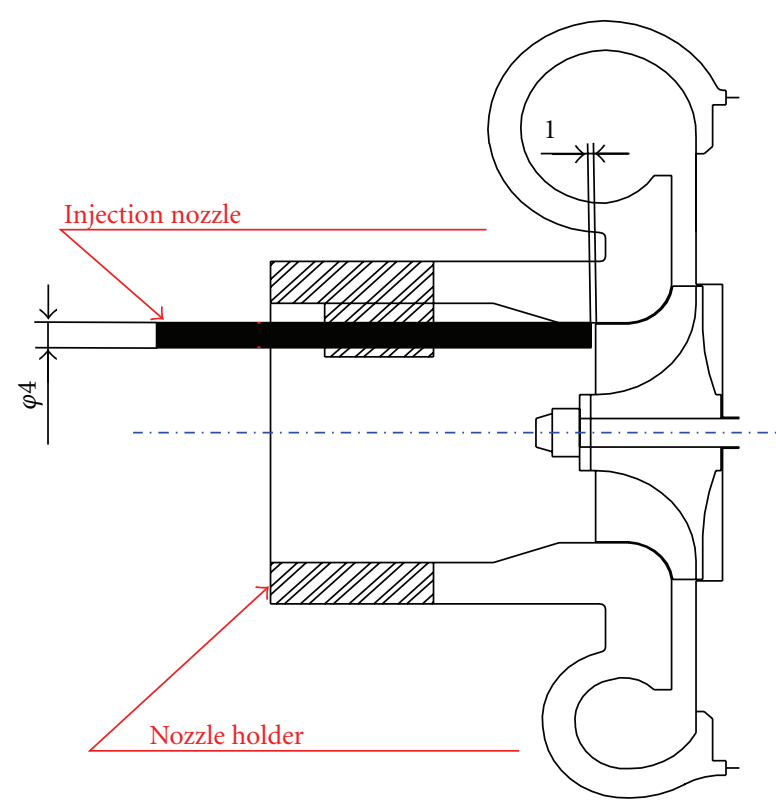

FIGURE 3: Injection nozzle (unit: mm).

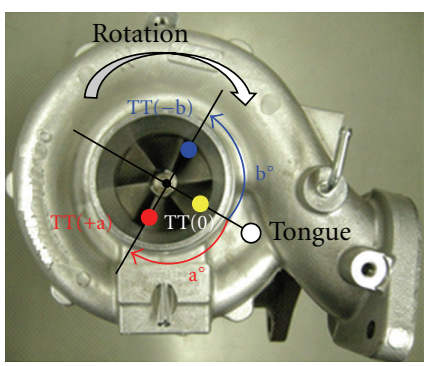

(a) Type A

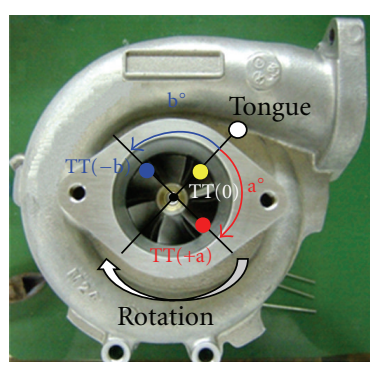

(b) Type B
FIGURE 4: Definition for position of injection nozzle. 


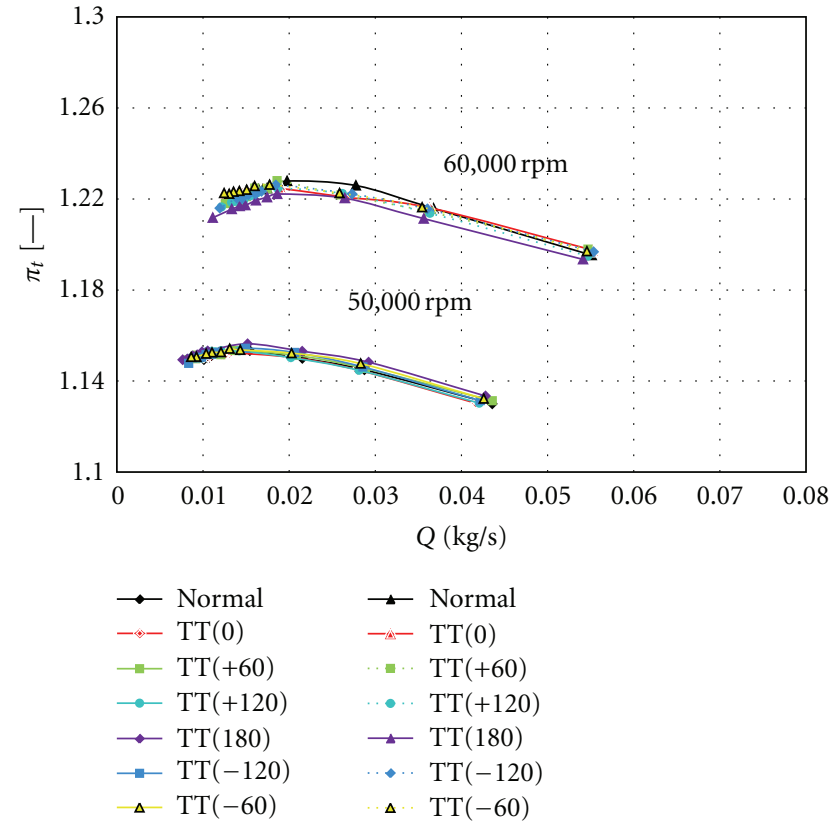

(a) Type A

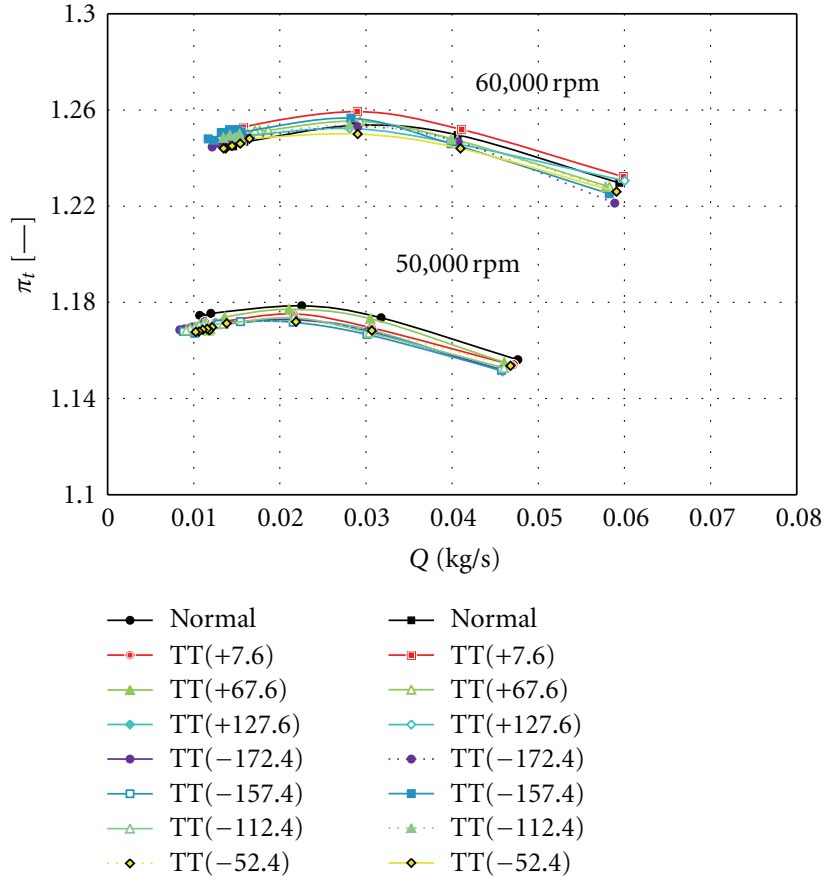

(b) Type B

Figure 5: Performance characteristics.

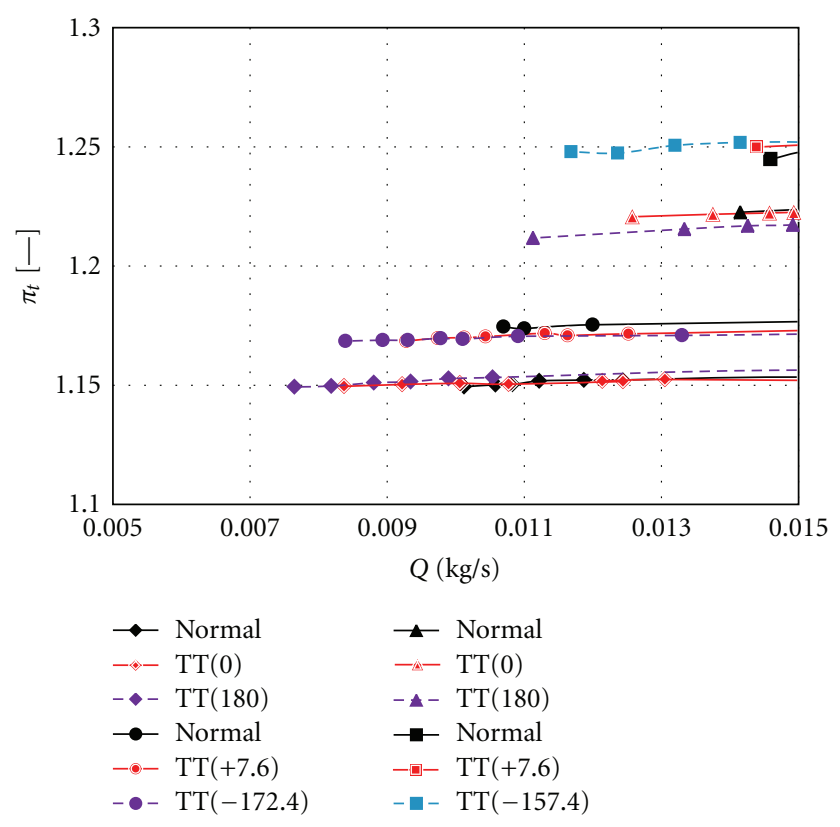

FIgURE 6: Performance characteristics at low flow rate.

impeller. In the following, the case with the injection nozzle is named "Injection," and that without the injection nozzle is named "Normal." The performance tests of compressors were performed at the corrected rotational speed of $50,000 \mathrm{rpm}$ and $60,000 \mathrm{rpm}$. In each experiment, the flow rate was decreased gradually from the full opening condition by closing the gate valve installed at the downstream side of the delivery duct, until the surge inception. In this study, the preexperiments were performed to relate the degree of the gate valve opening to the flow rate. The limiting flow rate for the surge inception is defined as the flow rate at the degree of valve opening opened by its minimum revolution from that at which a sudden increase of the pressure fluctuation caused by the surge is observed. In this study, the surge inception was detected by the observation of the pressure fluctuation caused by the surge, which was suddenly increased by gradually closing the valve by its minimum revolution. In the experiments for Injection, the experiments were carried out at every 30 degrees of TT from TT(0). Moreover, the experiments for Type B were made at 15-degree intervals around the optimum TT which remarkably reduced the limiting flow rate for surge inception. The exit of the injection nozzle was located at $1 \mathrm{~mm}$ upstream of the inlet of the impeller for every experimental condition of Injection. The thermocouples were used to measure the temperature at both the inlet and outlet of the compressor. The static pressure at delivery duct and the pressure difference across the orifice were measured by the pressure transducer. The uncertainty for the measured pressure data is $\pm 5 \mathrm{kPa}$. The corrected flow rate $Q$ and the pressure ratio $\pi_{t}$ were defined by the following equations:

$$
\begin{gathered}
Q=Q_{0} \frac{P_{a 0}}{P_{a}} \sqrt{\frac{T_{1}}{T_{0}}}[\mathrm{~kg} / \mathrm{s}], \\
\pi_{t}=\frac{P_{t}}{P_{a}}[-],
\end{gathered}
$$




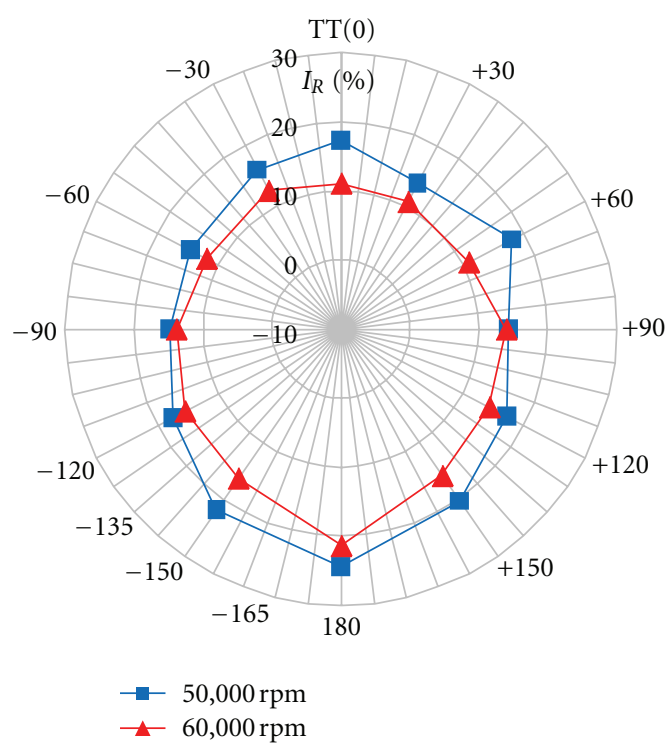

(a) Type A

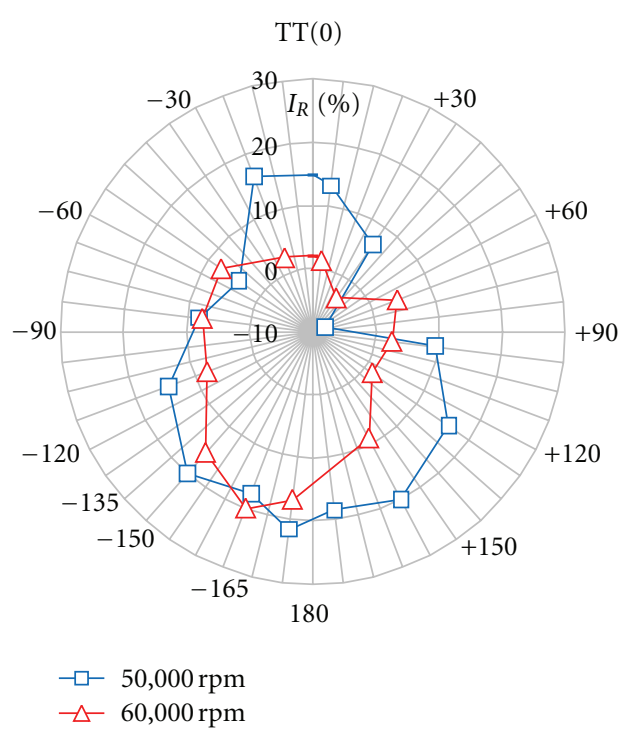

(b) Type B

FIGURE 7: Improvement rate of surge margin.
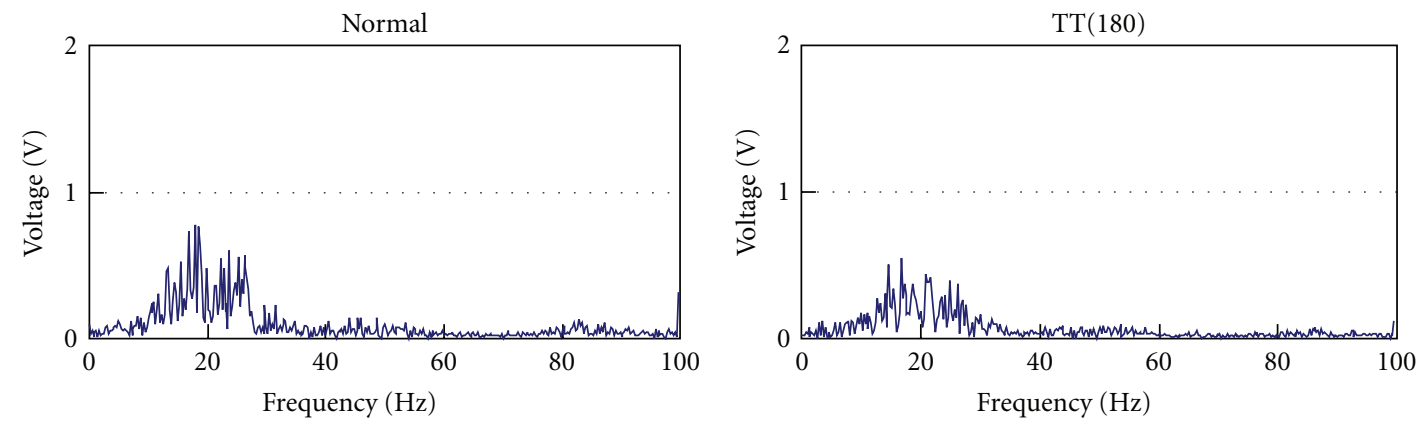

(a) $50,000 \mathrm{rpm}(Q \fallingdotseq 0.010 \mathrm{~kg} / \mathrm{s})$
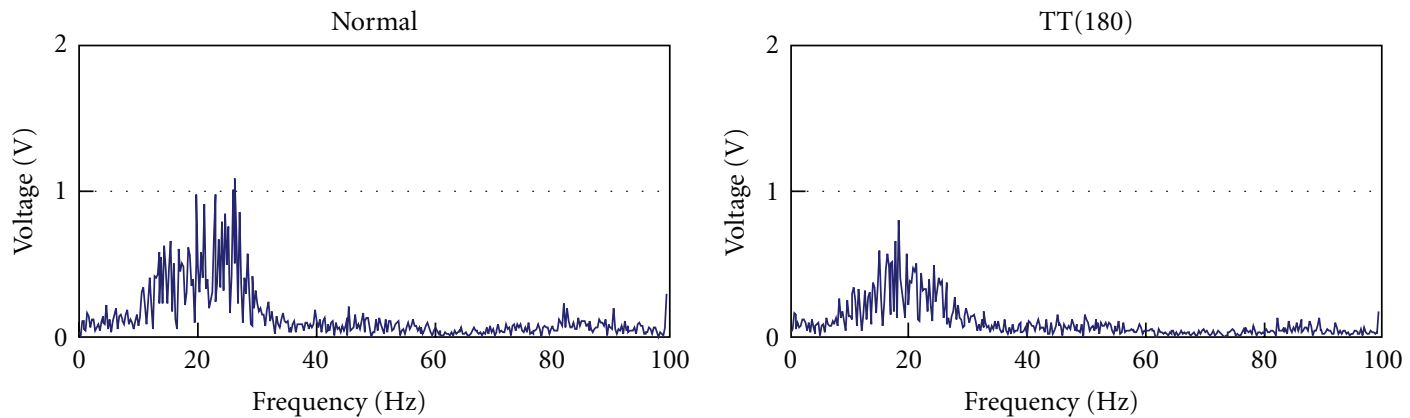

(b) $60,000 \mathrm{rpm}(Q \fallingdotseq 0.014 \mathrm{~kg} / \mathrm{s})$

FIGURE 8: Spectrum of pressure fluctuation at delivery duct.

where $Q_{0}$ is the measured flow rate, $P_{a 0}$ is the standard atmospheric pressure, $P_{a}$ is the measured atmospheric pressure, $T_{1}$ is the measured temperature, $T_{0}$ is the standard temperature, and $P_{t}$ is the measured total pressure at the compressor outlet. In order to investigate the unstable phenomena, the wall static pressure fluctuation was measured at $1800 \mathrm{~mm}$ downstream of the compressor exit. The frequency characteristics of the wall static pressure fluctuation were analyzed by performing FFT. Flow sensor was installed at the bypass pipe to measure the flow rate ejected from the injection nozzle.

\section{Results and Discussion}

4.1. Performance Characteristics. Figure 5 shows the performance characteristics for Normal and Injection of Type 

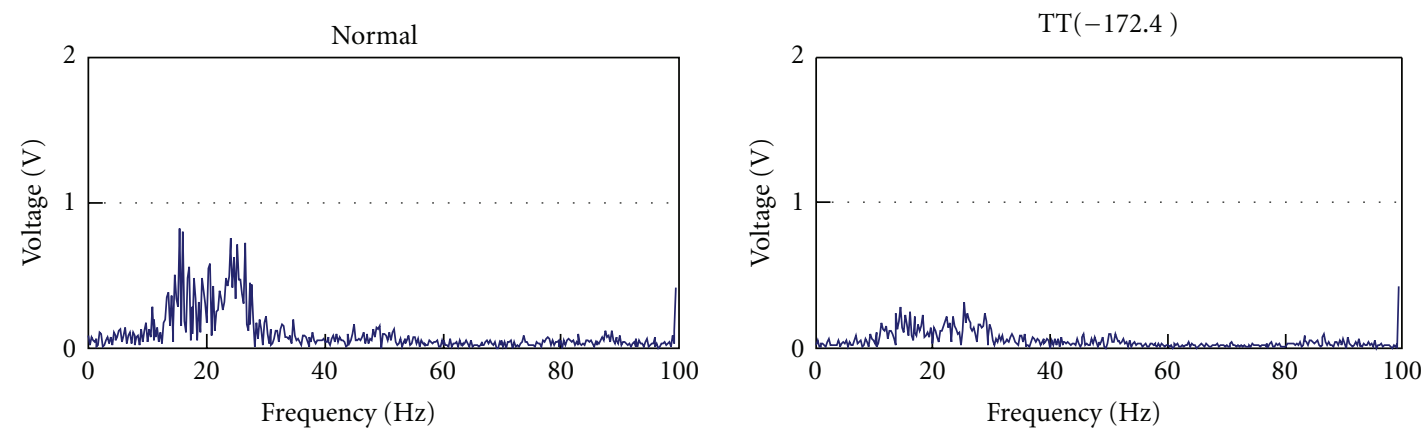

(a) $50,000 \mathrm{rpm}(Q \fallingdotseq 0.011 \mathrm{~kg} / \mathrm{s})$
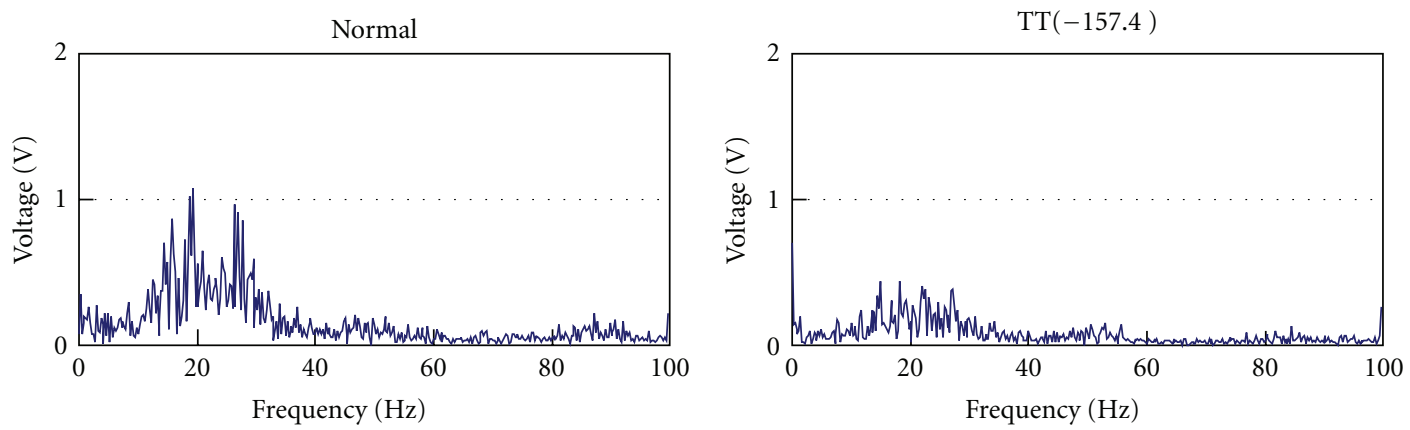

(b) $60,000 \mathrm{rpm}(Q \fallingdotseq 0.011 \mathrm{~kg} / \mathrm{s})$

FIgURE 9: Spectrum of pressure fluctuation at delivery duct for Type B.

TABLE 1: Specifications of impeller.

\begin{tabular}{lcc}
\hline Type of compressor & A & B \\
\hline Inlet diameter $(\mathrm{mm})$ & 43.38 & 45 \\
Outlet diameter $(\mathrm{mm})$ & 56 & 60 \\
Number of blades & 12 & 12 \\
Outlet blade angle (deg.) & 40 & 60 \\
Inlet blade height $(\mathrm{mm})$ & 15.4 & 14 \\
Outlet blade height $(\mathrm{mm})$ & 4.08 & 5.6 \\
Blade thickness $(\mathrm{mm})$ & 0.4 & 0.675 \\
\hline
\end{tabular}

$A$ and Type B at rotational speeds of 50,000 rpm and $60,000 \mathrm{rpm}$. Figure 6 shows the performance characteristics at the low flow rate region for $\mathrm{TT}(0)$ and $\mathrm{TT}(180)$ of Injection, which remarkably reduced the limiting flow rate for surge inception as shown later, with that for Normal.

The performance curves for Injection almost coincide with those for Normal in both Type A and Type B for every rotational speed (Figure 5). Therefore, it is apparent that the influence of the injection system on the performance characteristics of the compressor is negligible. Moreover, the limiting flow rate for surge inception is reduced by using the nozzle injection system as shown in Figure 6. Therefore, the nozzle injection system is recognized to have ability to extend the stable operating range to the lower flow rate region. It is considered that the injection on the inner wall of the suction pipe of the impeller would reduce the reversed flow region distributed on the shroud side wall from the diffuser exit up to the impeller inlet which appeared before the surge inception and consequently extend the limiting flow rate for surge inception to the lower flow rate region.

4.2. Optimal Injection Position. In order to evaluate the effect of injection on the reduction of limiting flow rate for surge inception, the improvement rate of surge margin $I_{R}$ was defined by the following equation:

$$
I_{R}=\frac{Q_{N}-Q_{I}}{Q_{N}} \times 100[\%],
$$

where $Q_{N}$ and $Q_{I}$ mean the limiting flow rate for surge inception in Normal and Injection, respectively. Figure 7 gives the relationship between the injection position TT and the improvement rate $I_{R}$.

The improvement rates $I_{R}$ at 50,000 rpm are relatively higher than those at 60,000 rpm in both Type A and Type B. The $I_{R}$ in Type A exhibits the improvement rate more than $10 \%$ for every TT, and the maximum $I_{R}$ more than $20 \%$ is achieved especially for TT(180) at each rotational speed (Figure 7(a)). Similar tendency is also observed in Type B (Figure 7(b)), and the maximum improvement rate more than $20 \%$ is located around TT(180) at both $50,000 \mathrm{rpm}$ and $60,000 \mathrm{rpm}$. These results suggest that the optimum circumferential position of the injection nozzle, which produces the maximum improvement ratio, is located around TT(180), which is the opposite side of the tongue of the scroll against the rotational axis, without the dependencies on the compressor type and the rotational speed. In general, the number of stall cell in the diffuser under the rotating stall condition varies from one to two according to the decrease 

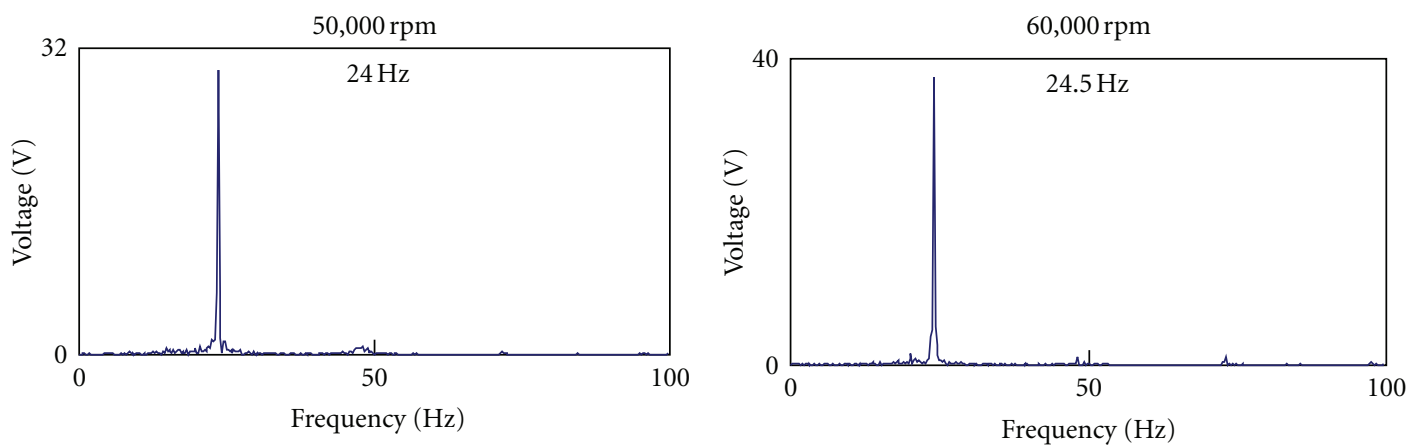

(a) Normal
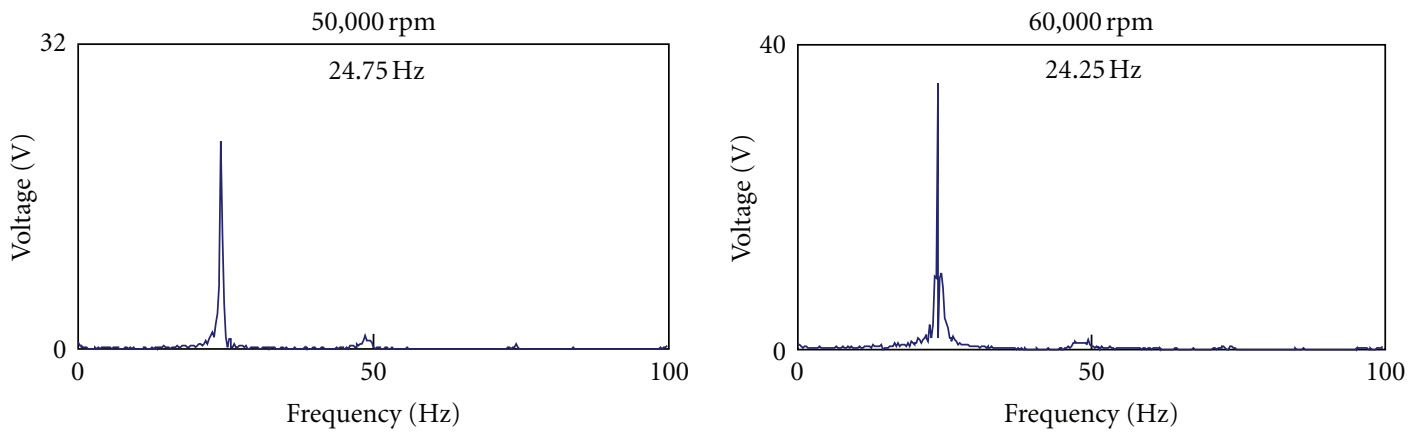

(b) $\mathrm{TT}(0)$
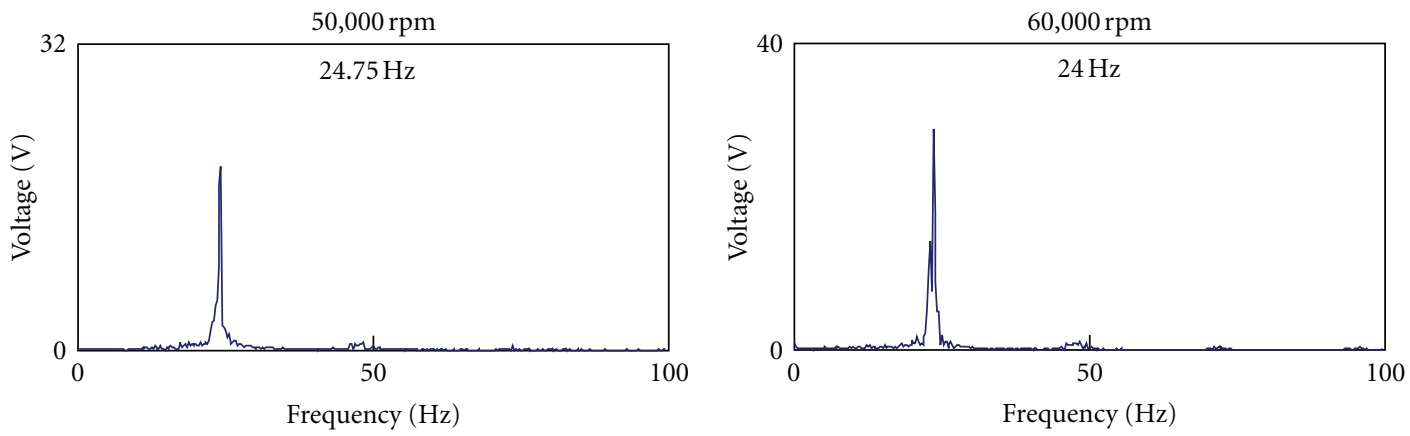

(c) $\mathrm{TT}(180)$

FIgURE 10: Spectrum of pressure fluctuation at delivery duct during surge for Type A.

of the flow rate. Moreover, in the case of the compressor with a scroll, the circumferential distribution of the static pressure on the diffuser endwall becomes nonaxisymmetric and is strongly distorted by the decrease of the flow rate. This distortion of the pressure distribution in the diffuser influences the flow field in the impeller, and consequently on the flow rate for surge inception. Therefore, it is considered that the optimum circumferential position of the injection nozzle has a strong relation with the behavior of the stall cell and the formation of circumferential distribution of the static pressure in the diffuser.

\subsection{Frequency Characteristic}

(a) Before Surge Inception. Figures 8 and 9 show the frequency characteristics of the static pressure fluctuation on the inner wall of the delivery duct at $1800 \mathrm{~mm}$ downstream of the compressor exit for Normal and the optimum TT of Injection in Type A and Type B, respectively. The flow rate in the results shown in Figures 8 and 9 is the nearest one to the limiting flow rate for surge inception for Normal. The peaks of the spectrum of pressure fluctuation for Normal at each rotational speed in Type A and Type B are observed around 15 to $30 \mathrm{~Hz}$. The peaks for the optimum TT of Injection are lower than those in Normal. The surge frequencies in Type A and Type B are about $24.5 \mathrm{~Hz}$ and $23.5 \mathrm{~Hz}$, respectively, irrespective of the rotational speed, which are different from the frequencies for the peaks observed in Figures 8 and 9. So, the peaks in Figures 8 and 9 are considered to be associated with the unstable phenomenon such as the rotating stall which appears before the surge inception. Therefore, it is considered that the optimum TT of Injection enhances the improvement rate of surge margin by suppressing the unstable phenomenon appearing before the surge inception. 


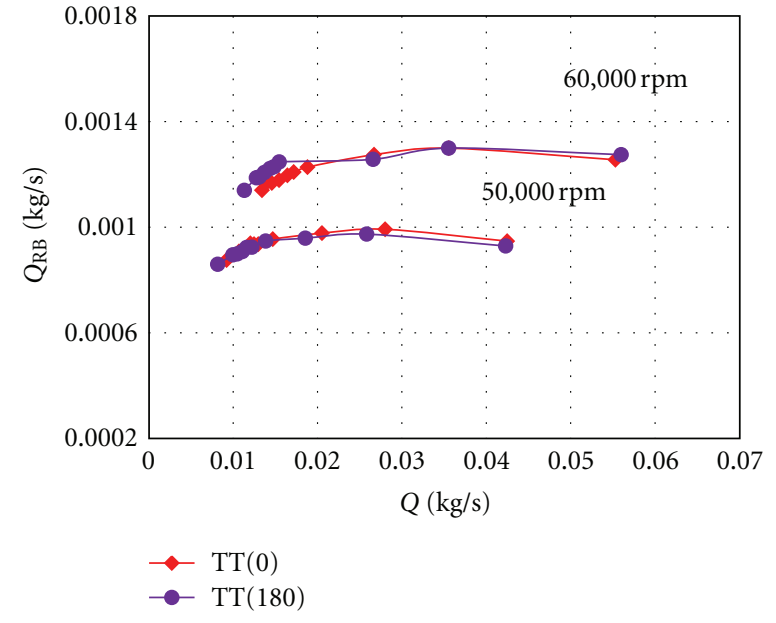

(a) Type A

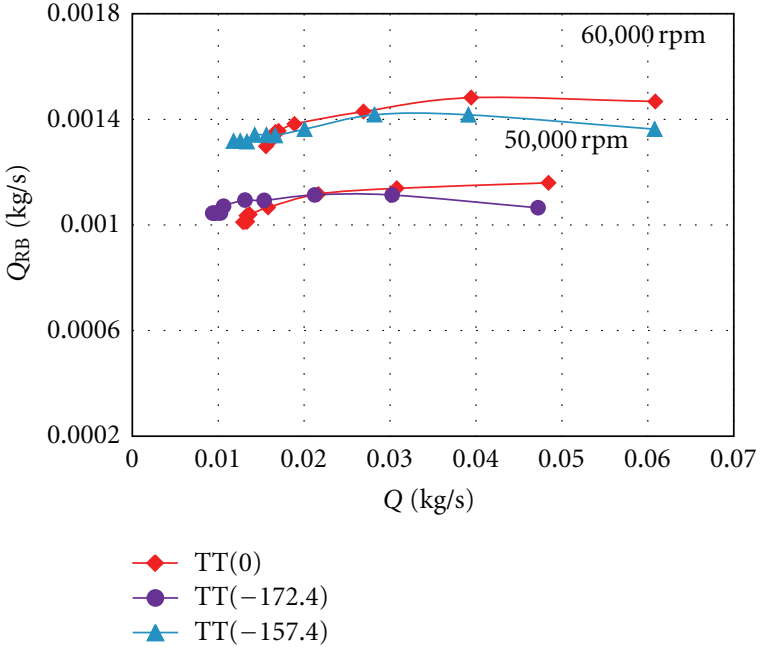

(b) Type B

FIGURE 11: Injection mass flow rate.

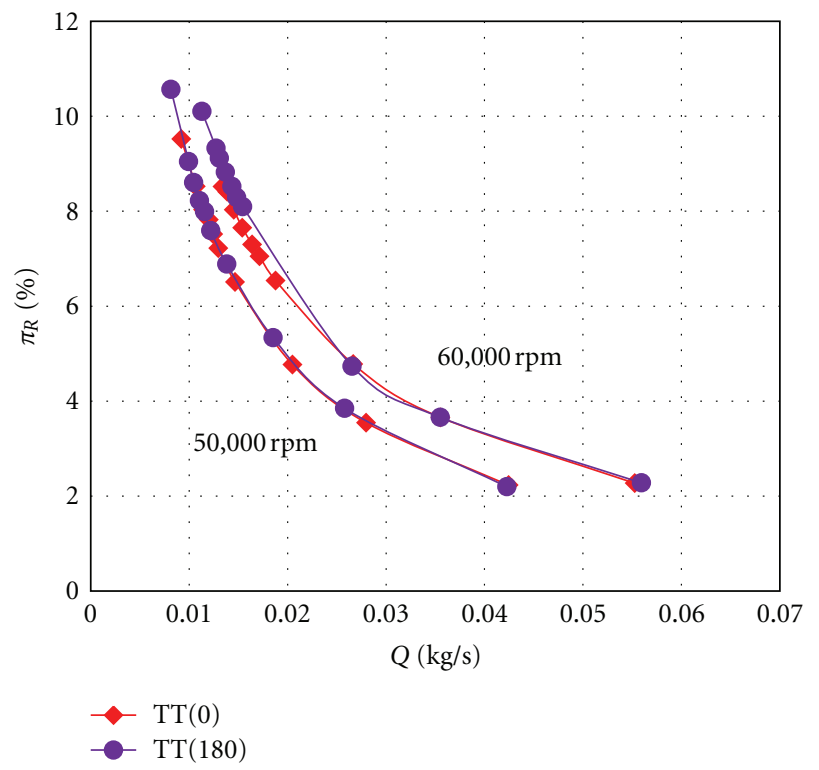

(a) Type A

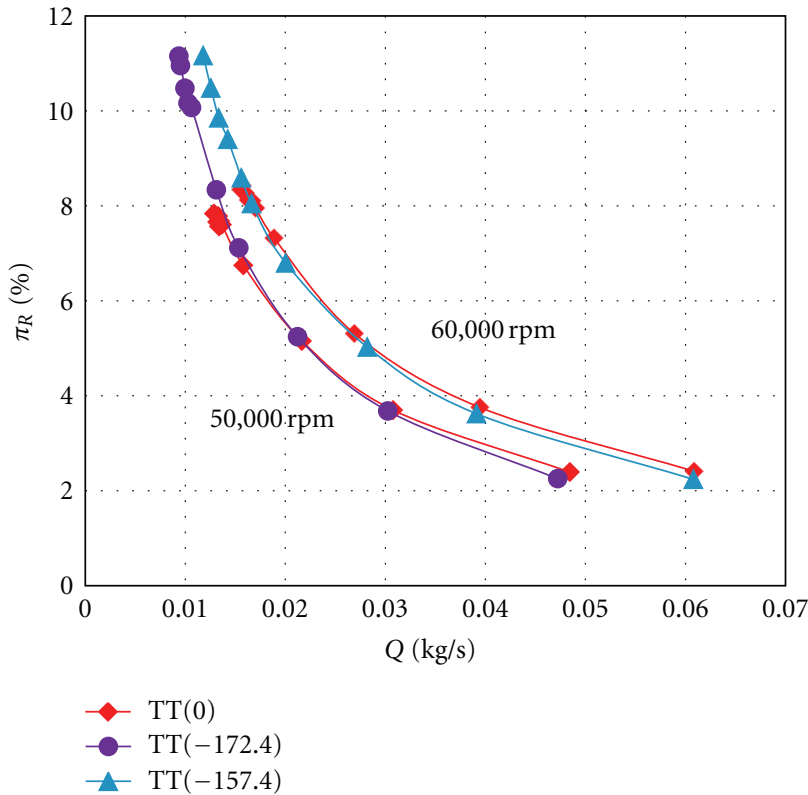

(b) Type B

FIgURE 12: Recirculation ratio.

(b) After Surge Inception. In order to examine the effects of the injection on the flow field under the surge condition, the frequency characteristics for Normal, TT(0), and the optimum TT(180) of Injection in Type A at $Q=0.000 \mathrm{~kg} / \mathrm{s}$ after the surge inception are given in Figure 10 . " $Q=$ $0.000 \mathrm{~kg} / \mathrm{s}$ " means the fully closed vane condition.

It is recognized that the peak of spectrum for the surge frequency of Injection becomes less than that of Normal after the surge inception. Moreover, the optimum $\mathrm{TT}(180)$ more reduces the peak of spectrum than TT(0). This means that Injection also reduces the strength of the surge, and the optimum circumferential position of injection for the surge reduction coincides with that for the reduction of the limiting flow rate for the surge inception.

4.4. Injection Flow Rate. Figure 11 shows the injection mass flow rate $Q_{\mathrm{RB}}$ for $\mathrm{TT}(0)$ and the optimum $\mathrm{TT}(180)$ of Injection at $50,000 \mathrm{rpm}$ and $60,000 \mathrm{rpm}$ in Type $A$ and Type B. The injection flow rate in each condition is almost constant over the full operating range, but increased by the increase of the rotational speed. This is caused by the increase of pressure ratio due to the increase of the rotational speed. On the other hand, the injection flow rate is almost 
unaffected by the circumferential position of injection TT at each rotational speed.

In order to evaluate the ratio of the injection mass flow rate to the mass flow rate discharged from the delivery duct, the recirculation ratio $\pi_{R}$ was defined by the following equation:

$$
\pi_{R}=\frac{Q_{\mathrm{RB}}}{Q_{N}} \times 100[\%] .
$$

Figure 12 shows the recirculation ratio $\pi_{R}$ for $\mathrm{TT}(0)$ and the optimum TT(180) of Injection at 50,000 rpm and $60,000 \mathrm{rpm}$ in Type A and Type B. The influence of the circumferential position of injection TT on the recirculation ratio $\pi_{R}$ is very small. The recirculation ratio is increased by the decrease of the flow rate in every experimental condition. Moreover, the comparison between the rotational speeds indicates that the recirculation ratio $\pi_{R}$ is increased by the increase of the rotational speed corresponding to the tendency observed for the injection mass flow rate (Figure 11).

\section{Conclusion}

The following conclusions were obtained by the present study.

(1) With the nozzle injection system the stable operating range of the compressor improves and that is a direct effect on the performance characteristic.

(2) The optimum circumferential position of the injection nozzle, which produces the maximum improvement rate, is located around the opposite side of the tongue of the scroll against the rotational axis irrespective of the compressor type and the rotational speed.

(3) The optimum circumferential position of Injection enhances the improvement rate of surge margin by suppressing the unstable phenomenon appearing before the surge inception.

(4) The injection flow rate is almost constant over the full operating range, but increased by the increase of the rotational speed.

(5) The nozzle injection system has also the ability to reduce the strength of the surge.

(6) The optimum circumferential position of Injection for the surge reduction coincides with that for the reduction of the limiting flow rate for the surge inception.

\section{References}

[1] A. Suzuki, H. Tsujita, and S. Mizuki, "Passive control of surge for centrifugal compressor by using resonator," in Proceedings of the 4th International Symposium on Experimental and Computational Aerothermodynamics of Internal Flows, vol. 2, pp. 226-233, 1999.
[2] H. Tamaki, X. Zheng, and Y. Zhang, "Experimental investigation of high pressure ratio centrifugal compressor with axisymmetric and non-axisymmetric recirculation device," in Proceedings of the ASME International Gas Turbine Institute (IGTI'12), 2012.

[3] S. Mizuki, H. Tsujita, and Y. Hishinuma, "Control of surge for centrifugal compression system by using a bouncing ball," ASME Paper 2000-GT-429, 2000.

[4] F. Willemas and B. De Jager, "One-sided control of surge in a centrifugal compressor system," ASME Paper 2000-GT-527, 2000.

[5] G. J. Skoch, "Experimental investigation of diffuser hub injection to improve centrifugal compressor stability," NASA/TM 2004-213182, 2004.

[6] H. Chen and V. Lei, "Casing treatment \& inlet swirl of centrifugal compressors," in Proceedings of the ASME International Gas Turbine Institute (IGTI '12), 2012.

[7] R. Gu and M. Yashiro, "Surge control for centrifugal compressor of turbocharger," JSAE Paper, vol. 36, no. 2, pp. 83-88, 2005.

[8] R. Gu, H. Ikeda, A. Yoshida, H. Tsujita, and S. Mizuki, "Effect of air injection on performance characteristics of small centrifugal compressor," in Proceedings of the Turbomachinery Society of Japan, May 2007.

[9] R. Gu, S. Mizuki, and H. Tsujita, "Surge control of centrifugal compressor by inducer tip injection," in Proceedings of the International Gas Turbine Congress (IGTC '07), Tokyo, Japan, 2007. 

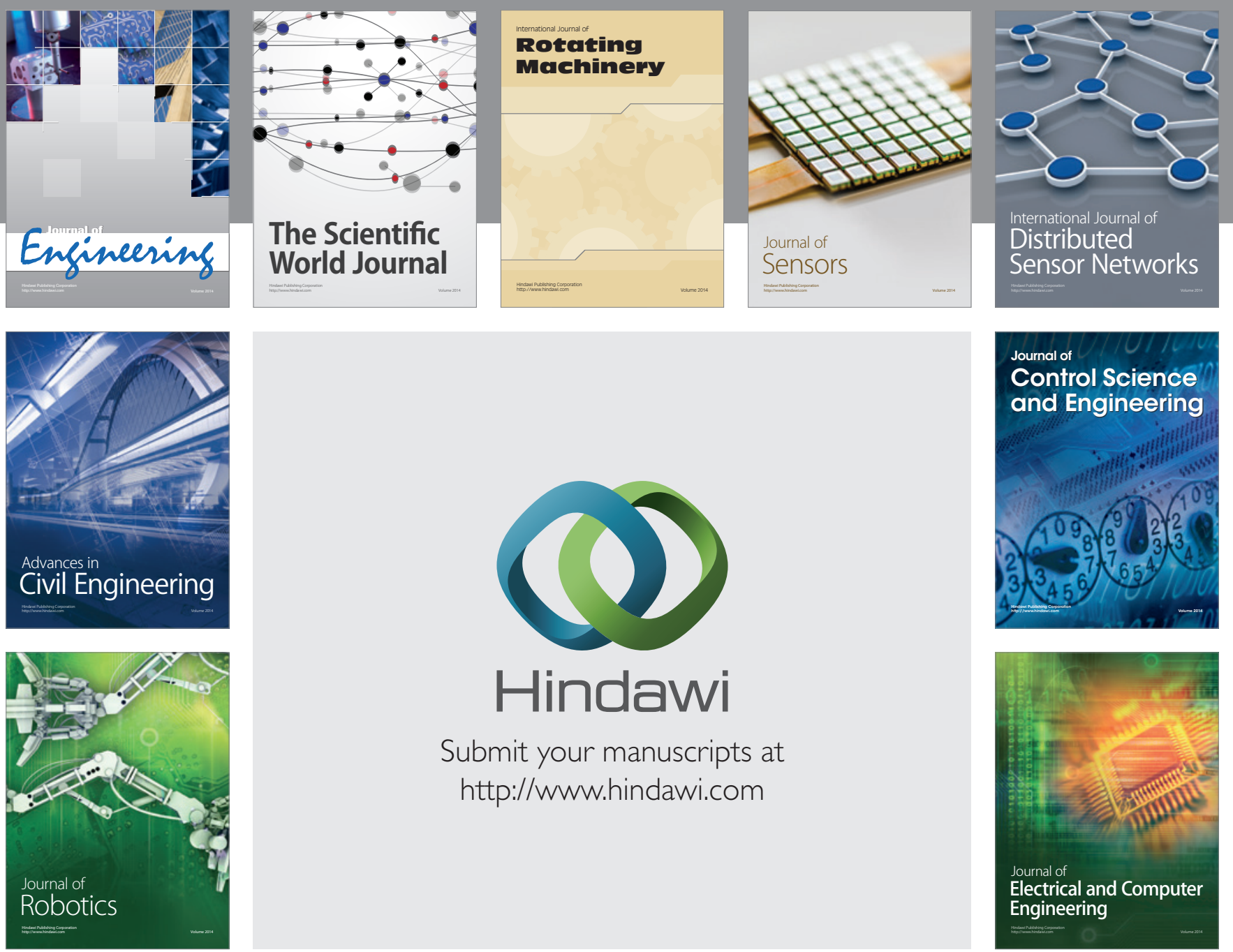

Submit your manuscripts at

http://www.hindawi.com
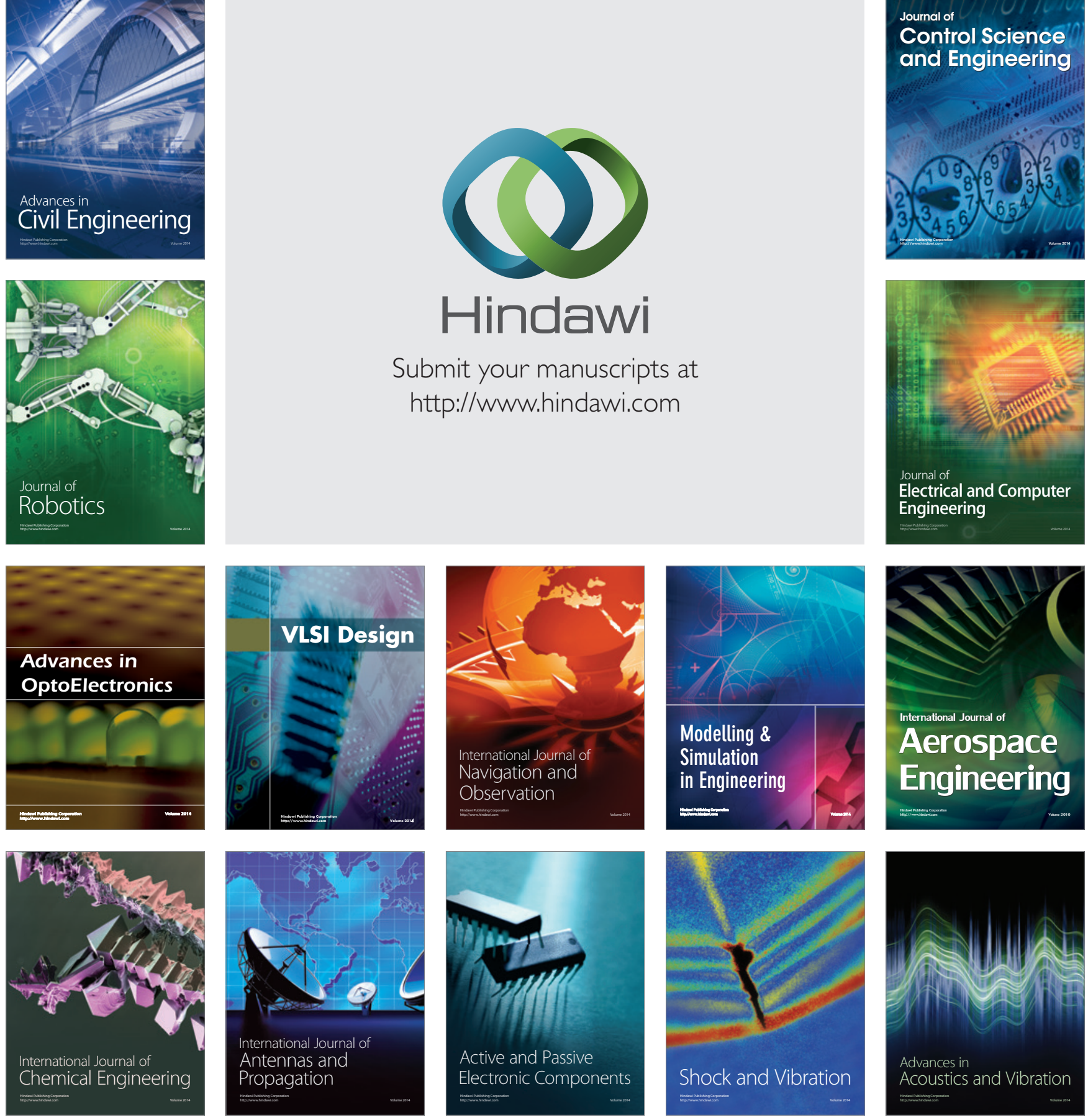